\title{
Development of durable shrink-resist coating of wool with sol-gel polymer
}

\section{processing}

\author{
Jinsong Shen*, Edward Smith, Mutinta Chizyuka and Chetna Prajapati \\ Textile Engineering and Materials (TEAM) Research Group, School of Design, De Montfort \\ University, Leicester, LE1 9BH, UK
}

\begin{abstract}
Knitted wool fabric was pre-treated with the serine type protease, Esperase 8.0L (EC3.4.21.62), and sodium sulphite followed by an immersion treatment with a sol-gel hybrid polymer. To enhance the durability of the sol-gel treatment on wool, one of two different alkoxysilane containing coupling epoxy or mercapto groups were added to the sol-gel hybrid. The combination of protease treatment with an immersion sol-gel treatment achieved wool fabric that was lightweight with a soft handle and had combined shrink-resistance and hydrophobic properties without fibre discoloration. The addition of an alkoxysilane with a mercapto coupling group within the sol-gel hybrid gave better performance than using an alkoxysilane with an epoxy coupling group in terms of polymer uptake, fabric shrink resistance, whiteness and durability to washing.
\end{abstract}

Keywords: Wool, Sol-gel, Alkoxysilanes, Enzymes, Protease, Shrink-resistance 


\section{Introduction}

Wool fabric has natural warmth, soft handle and a hydrophobic character meaning it is an ideal choice for use in outerwear garments. However, a major drawback of wool is its tendency to felt and shrink when washed, due to the configuration of cuticle scales on the surface of wool fibre. The conventional chemical process consists of degrading the cuticle scales by a chlorination process followed by a polymer deposition process to mask the scales. This process has major drawbacks in which chlorination contaminates waste water with absorbable organic halides (AOX) and if the chlorination step is omitted, increased polymer deposition is required resulting in a product with a harsh handle. Therefore, the demand for more environmentally friendly wet processing methods for wool has increased. Proteolytic enzymes have been suggested for incorporation in wool processing for improving scouring efficiency, handle properties and imparting shrink resistance [1]. Proteolytic enzymes promote the hydrolysis of proteins, therefore breaking down the cuticle scales on the wool fibre surface. However, if not carefully controlled this enzymatic process can cause significant damage to the wool fibre due to the enzyme penetrating into and attacking the fibre core $[2,3]$. To restrict the enzyme attack to the cuticle scales and prevent damage to the fibre, methods of either modifying the treatment process [4-7] or enlarging the proteolytic enzyme by chemical [8-10] or genetic modification [11] have been investigated but a viable commercial process is not currently available.

In recent years there has been an increasing interest in the development of sol-gel techniques for textiles. Multi-functionality can be achieved on textile fabric through a single sol-gel hybrid polymer coating process, depositing nanocomposite polymer films on the surface of individual fibres. Physical properties on the treated textile fabrics such as tensile strength, softness, elasticity and breathability are claimed to be retained due to the polymer film being 
extremely thin and porous [12]. The multifunctional effects that can be achieved depend on the precursors used in sol-gel synthesis. The sol-gel process consists of the hydrolysis of metal alkoxide compounds through the formation of a colloidal suspension, sol, followed by a condensation stage resulting in the gelation of a sol to form a matrix. Alkyl alkoxysilanes are the most common precursors for the sol-gel process. Functional properties investigated by sol-gel application on fabric have included water and/or oil repellence, anti-microbial resistance, ultraviolet resistance, abrasion resistance, flame resistance, coloration, or encapsulation of active materials [13]. Modified silica nanosols containing long chain alkyl alkoxysilanes have been used as a low temperature coating process to achieve a nonfluorinated superhydrophobic surface [14-16]. The addition of GPTMS (3-glycidyloxypropyl trimethoxysilane) has been considered for durability on cotton substrates $[15,16]$. There is the potential of using sol-gel to achieve shrink-resistance of wool which has only been considered previously in a few studies [17-19]. Textor et al. [17] observed that wool fabrics finished with a sol-gel based on GPTMS did not show any felting after a laundry washing of $60^{\circ} \mathrm{C}$. Yan et al. [18] investigated treating wool gabardine woven fabric with a GPTMS solgel and found durable anti-felting could be achieved if the sol-gel treated fabric was cured at temperatures up to $180^{\circ} \mathrm{C}$. Yi and Yan [19] prepared a sol from a PPT-[Si(OEt $\left.)_{3}\right]_{3}$ precursor which was treated on wool using a pad-dry-cure process and found that an anti-felting effect could be achieved with a curing temperature as low as $120^{\circ} \mathrm{C}$. It was stated that curing the sol-gel treatment on wool decreased the whiteness of wool and that whiteness decreased as curing temperature increased.

In the current work, it was considered whether the combination of proteolytic enzyme processing and hybrid sol-gel coating of knitted wool fabric could achieve combined shrinkresist and hydrophobic properties along with light-weight and a soft handle without 
discoloration of the fibre. Previous studies have shown that proteolytic enzyme treatment of wool improves the whiteness of the fibre [4]. A synthesised hybrid sol-gel containing the alkyl alkoxysilane precursors; methyl triethoxysilane (MTES), octyl triethoxysilane (OTES) and dimethyloctadecyl [3-(trimethoxysilyl)propyl] ammonium chloride (QUAT) and a novel application method, originally developed for achieving hydrophobic and antimicrobial cotton [20], was applied to wool fabric. As opposed to the conventional dip and pad application used in sol-gel application [16], the sol-gel application method developed by Chizyuka [20] involved prolonged contact between fabric and sol-gel through the full immersion of fabric in the sol-gel solution under agitation enabling the sol-gel polymer network to grow on individual fibres, therefore achieving a soft fabric handle. MTES should act as the building block for preparing the silicate network of the hybrid sol-gel enabling the coating to be flexible on account of the short alkyl chain. It is claimed that MTES gives rise to porous coatings with rough surfaces [21]. The long alkyl chains on OTES and QUAT make fabric treated with the hybrid sol-gel more hydrophobic and QUAT also gives anti-microbial properties to the treated fabric [20]. To enhance durability to washing when applied onto wool, one of two different alkoxysilanes containing coupling groups suitable for reacting with the functional groups on the wool fibre surface was added to the hybrid sol and their properties were compared on the treated wool fabric. The two coupling groups considered were an epoxy group or a mercapto group, found in 3-glycidyloxypropyl trimethoxysilane (GPTMS) and 3-mercaptopropyl trimethoxysilane (MPTMS) respectively.

\section{Materials and Methods}

\section{Materials}

Fabric, supplied by Lokateks (Skofja Loka, Slovenia), was made from 100\% wool with a mean fibre diameter of $21.9 \mu \mathrm{m}$ spun into a $40 \mathrm{Nm}$ single yarn and constructed as a fine rib 
1:1 knit with a dry weight of $220 \mathrm{~g} / \mathrm{m}^{2}$. Alkyl alkoxysilanes including, methyl triethoxysilane (MTES), octyl triethoxysilane (OTES), 3-glycidyloxypropyl trimethoxysilane (GPTMS), 3mercaptopropyl trimethoxysilane (MPTMS) and dimethyloctadecyl [3(trimethoxysilyl)propyl] ammonium chloride (QUAT) were all purchased from SigmaAldrich (Dorset, UK). Ultravon PL, a non-ionic surfactant containing a fatty alcohol ethoxylate, was a Huntsman Textile Effects product purchased from Town End plc (Leeds, UK). The alkaline protease, Esperase 8.0L (EC 3.4.21.62) was supplied by Novozymes A/S (Bagsvaerd, Denmark).

\section{Pre-treatment of wool fabric}

Fine-rib 1:1 knitted wool fabric was pre-treated in a $0.02 \mathrm{M}$ borate buffer set at $\mathrm{pH} 8.5$ containing $2 \mathrm{~g} / \mathrm{L}$ of the non-ionic surfactant Ultravon PL with or without the presence of either sodium sulphite or Esperase and sodium sulphite. All three pre-treatment conditions were undertaken at liquor to goods ratio of $40: 1$ for 30 minutes at $60^{\circ} \mathrm{C}$ using a Datacolor Ahiba Nuance Top Speed II infrared dye machine with the agitation set at $40 \mathrm{rpm}$. The samples were rinsed thoroughly with water, then hydro-extracted to remove excess water and left to dry at room temperature.

\section{Sol-gel synthesis}

Sol-gel was prepared by first adjusting $300 \mathrm{~mL}$ of a $50 \% \mathrm{v} / \mathrm{v}$ ethanol solution to $\mathrm{pH} 3.2$ with $1 \mathrm{M}$ hydrochloric acid. To the ethanol solution under constant stirring, $30 \mathrm{~mL}$ of MTES, 5 mL of either GPTMS or MPTMS, $10 \mathrm{~mL}$ of OTES and $5 \mathrm{~mL}$ of QUAT (at the ratio of $30: 5$ : $10: 5)$ were added dropwise. The resultant mixture was stirred continuously for a total of 4 hours at room temperature. After the 4 hour reaction time, the synthesised sol-gel became clear and colourless. 


\section{Application of sol-gel on wool fabric}

Synthesised sol-gel was diluted with deionised water in a 1:1 or a 2:1 ratio of sol-gel to water. The pre-treated knitted wool fabrics were treated in the diluted sol-gel at the liquor to goods ratio of $25: 1$ at $40^{\circ} \mathrm{C}$ under agitation of $20 \mathrm{rpm}$ for 4 hours using a Datacolor Ahiba Nuance Top Speed II infrared dye machine.

To ensure consistent liquor pick-up, treated wool fabric samples were passed through an Ernst Benz laboratory pad mangle twice at a pressure of $45 \mathrm{~kg} / \mathrm{cm}$ at a speed of $1 \mathrm{~m} / \mathrm{min}$. The padded wool fabric samples were dried at ambient temperature overnight. For further curing, the treated wool samples were dried at $70^{\circ} \mathrm{C}$ for 5 minutes in a fan operated oven followed by curing at $120^{\circ} \mathrm{C}$ for 20 minutes. After curing, the samples were allowed to cool overnight and rinsed in water at $24^{\circ} \mathrm{C}$ for 30 minutes under agitation of $20 \mathrm{rpm}$ in a Datacolor Ahiba Nuance Top Speed II infrared dye machine. The rinsed wool samples were then hydroextracted to remove excess water and dried in a fan operated oven at $40^{\circ} \mathrm{C}$ for 2 hours. The samples were then ready for property and performance testing.

\section{Weight change of textile samples}

The weight loss of the wool textile samples after pre-treatment was expressed as a percentage, $\mathrm{W}_{\mathrm{L}}$, and was calculated using Eq. (1):

$$
\% \mathrm{~W}_{\mathrm{L}}=100 \times\left(\mathrm{W}_{1}-\mathrm{W}_{2}\right) / \mathrm{W}_{1}
$$

where $\mathrm{W}_{1}$ is the weight of conditioned knitted wool fabric prior to pre-treatment and $\mathrm{W}_{2}$ is the weight of conditioned knitted wool fabric after pre-treatment.

The weight gain of the pre-treated knitted wool samples after sol-gel finishing was expressed as a percentage, $\mathrm{W}_{\mathrm{G}}$, and was calculated using Eq. (2):

$$
\% \mathrm{~W}_{\mathrm{G}}=100 \times\left(\mathrm{W}_{4}-\mathrm{W}_{3}\right) / \mathrm{W}_{3}
$$


where $\mathrm{W}_{3}$ is the weight of conditioned pre-treated knitted wool fabric prior to sol-gel finishing and $\mathrm{W}_{4}$ is the weight of conditioned pre-treated knitted wool fabric after sol-gel finishing.

\section{Whiteness}

The whiteness of the treated knitted wool fabric samples was determined in terms of the CIE Whiteness Index using a Datacolor Spectraflash SF600 Plus reflectance spectrophotometer. Each fabric sample was folded into four and measured four times. All values were measured and calculated using ColorTools QC software with illuminant and observer conditions of D65 and $10^{\circ}$, respectively.

\section{Shrinkage due to machine washing}

The measurement of area shrinkage due to washing of the treated knitted wool samples was tested according to Woolmark Test Method TM31: Washing of Wool Textile Products. Using an Electrolux Wascator FOM71 washing machine, the samples were subjected to a 7A wash cycle for relaxation shrinkage followed by $5 \mathrm{~A}$ washes up to 3 times for felting shrinkage. Weight loss due to washing was also determined and expressed as a percentage, $\mathrm{W}_{\mathrm{LW}}$, calculated using Eq. (3).

$$
\% \mathrm{~W}_{\mathrm{LW}}=100 \times\left(\mathrm{W}_{5}-\mathrm{W}_{6}\right) / \mathrm{W}_{5}
$$

Where $\mathrm{W}_{5}$ is the weight of conditioned knitted wool fabric prior to being subjected to series of machine wash cycles and $\mathrm{W}_{6}$ is the weight of conditioned knitted wool fabric after machine washing. 


\section{Bursting strength}

The bursting strength of the treated knitted wool samples after machine washing was measured according to ISO 13938-2:1999, using a James H Heal TruBurst 610 Bursting Strength Tester. A test area of $10 \mathrm{~cm}^{2}(35.7 \mathrm{~mm}$ diameter $)$ was used and the pressure rate was set at $20 \mathrm{kPa} / \mathrm{s}$. The mean bursting pressure, in $\mathrm{kPa}$, was recorded.

\section{Scanning Electron Microscopy (SEM) of treated wool fabric samples}

To determine the effect and extent of sol-gel coating to the surface of wool fibres and the durability of the coating after machine washing, micrographs of treated and untreated wool samples before and after machine washing were taken using SEM. Samples for SEM examination were prepared by attaching a double sided adhesive carbon tab to an aluminium stub, then laying wool fibre across the sticky surface of the stub and then sputter coated with gold under argon for 60 seconds using a Quorum Q150RS rotary-pumped sputter coater. Samples were examined using a Carl Zeiss EVO HD15 scanning electron microscope operating at an accelerating voltage of $10 \mathrm{kV}$, a working distance of between 8 and $9 \mathrm{~mm}$ and a magnification of either $2,500 x$ or $10,000 x$.

To identify the elemental content of the sol-gel coating applied to the surface of the wool fibres, Energy Dispersive X-ray (EDX) analysis was coupled to the SEM. Prior to gold coating, a still image was captured from the wool fabric samples in the pressured chamber after SEM and a selected area of interest was selected for EDX elemental analysis using Inca software.

\section{Fabric hydrophobicity}

The hydrophobicity of the fabric samples was characterised using the Water Rating Number, a test which was based on AATCC 193:2007, often referred to as the DuPont wettability test 
$[22,23]$. For the Water Rating Number test, a series of aqueous solutions containing different concentrations of iso-propanol (\% v/v) were prepared as detailed in Table 1. A drop of $20 \mu \mathrm{L}$ of test liquid was placed on the surface of the fabric using a dispensing pipette starting with the lowest concentration of isopropanol and repeated with higher concentrations, until the highest number was reached which did not wet the fabric surface in 10 seconds. The highest number was recorded as water rating number (WRN) for the fabric.

[Table 1 near here]

\section{Results and Discussion}

Knitted wool was pre-scoured with the non-ionic surfactant Ultravon PL (UPL) and then treated with sol-gel to see if the fibre could be coated effectively and whether shrinkresistance of the wool could be improved due to the sol-gel coating the cuticle surface of the wool. To ensure that the sol-gel would bind to the wool fibre surface, thus improving the durability of the coating, alkyl alkoxysilanes containing coupling groups were added to the sol-gel through either 3-glycidyloxypropyl trimethoxysilane (GPTMS) or 3-mercaptopropyl trimethoxysilane (MPTMS). GPTMS contains an epoxy group which should react with amino groups on the surface of the wool fibre [16] while the thiol group in MPTMS should react with sulphur groups found in the cysteine moieties of wool protein [24]. The possible reactions between wool and either GPTMS or MPTMS are illustrated respectively in Schemes 1 and 2. In addition, the GPTMS or MPTMS may form crosslinks between themselves within the sol-gel, potentially improving uniformity and durability of the coating.

[Schemes $1 \& 2$ near here]

Sol-gel containing GPTMS on undamaged scoured wool showed a low weight gain due to sol-gel treatment indicating a low polymer uptake (Table 2). The coating caused some 
improvement in shrinkage after 3x 5A washes in comparison to the control sample, from $16.61 \%$ to $7.35 \%$, but this would not meet commercial standards [25]. SEM showed that after repeated washes the surface coating containing GPTMS in the sol was washed off (Fig 1). It was assumed that that the sol-gel containing GPTMS was bonded weakly to the outmost lipid layer on the surface of the wool cuticle, resulting in low polymer uptake and poor durability due to washing. The presence of GPTMS in sol-gel coatings not improving the durability of the coating on wool was also observed by Wang et al. [16], but they observed an improved durability when used on cotton and polyester substrates.

Sol-gel containing MPTMS on undamaged scoured wool showed a higher weight gain than using GPTMS, resulting in better performance. The coating containing MPTMS enabled wool to achieve shrink-resistance with shrinkage of $1.31 \%$ after $3 \mathrm{x} 5 \mathrm{~A}$ washes. A significant improvement in the CIE Whiteness Index showed that the presence of MPTMS provides a whitening effect of wool. This concurs with a claim by Nickel et al. [26] that treating wool with an aqueous preparation containing organopolysiloxanes with mercaptoalkyl or mercaptoaryl radicals caused no yellowing to wool. The SEM, in Figure 1, showed that after repeated washing, sol-gel containing MPTMS was more durable than sol-gel containing GPTMS. It was considered whether better surface coating and durability of coating with solgel containing MPTMS could be achieved if the wool was pre-treated with sodium sulphite. Sulphite provides reducing conditions to break down the disulphide bonds in the cystine linkages on wool to form thiol groups; this therefore could promote the reaction between the thiol groups in MPTMS with those on the wool. Treatment of wool pre-treated with sodium sulphite with sol-gel containing MPTMS resulted in a higher polymer deposition and better durability to washing as illustrated on the SEM image in Figure 2. The SEM images in Figure 2 also show that sol-gel coating was deposited on individual fibres and therefore no 
crosslinking between fibres observed. This is why the handle of wool fabric was not affected noticeably.

[Figure 1, Figure 2 and Table 2 near here]

Knitted wool fabric was pre-treated with a proteolytic enzyme, Esperase, in the presence of a reducing agent, sodium sulphite, and a non-ionic surfactant, Ultravon PL, buffered at $\mathrm{pH} 8.5$ with borate buffer. The rate of enzymatic attack on wool with protease is relatively slow as long as the cysteine disulphide bond remains intact, but once these cross-links are broken in the presence of a reducing agent such as sodium sulphite, the reaction is greatly increased [27]. A weight loss of $17.98 \%$ was observed (see Table 2). The significant loss in weight was caused by the presence of the combination of protease and sulphite, as pre-treatment with Ultravon PL buffered to $\mathrm{pH} 8.5$ in a borate buffer with and without sodium sulphite showed a weight loss of less than $1 \%$. As previously observed $[4,10]$, protease can degrade cuticle scales on wool leading to an improvement of the shrink-resistance of wool but significant damage was caused in terms of the loss of weight and strength due to protease penetrating into the fibre. Further proof of the damage caused by protease to wool fabric was the further $21.78 \%$ weight loss incurred on the fabric during $3 \mathrm{x} 5 \mathrm{~A}$ washing cycles therefore showing that considerable fabric deterioration continues during washing. Burst strength was reduced significantly from $431 \mathrm{kPa}$ to $133 \mathrm{kPa}$.

Although proteolytic enzyme treatment in the presence of sodium sulphite causes significant damage to wool, it makes the fabric light with a soft handle as well as improving its shrink resistance. It was considered whether enzyme pre-treated knitted wool could be treated with a subsequent sol-gel coating potentially holding damaged wool fibres together and preventing further weight loss during washes. Knitted wool fabric which had been pre-treated with Esperase in the presence of sodium sulphite was subsequently treated with sol-gels containing 
either GPTMS or MPTMS. The subsequent sol-gel finishing showed excellent shrink resistance, with shrinkage levels of less than $1 \%$ achieved after $3 \times$ $5 \mathrm{~A}$ washes (see Table 2). The significant loss in weight during washing was reduced significantly suggesting less damage to the fabric. The SEM shown in Figure 3 confirms that severe damage to wool fibre treated with Esperase in the presence of sulphite occurs after repeat washing but that sol-gel coating can hold together the fibres damaged by the enzyme pre-treatment preventing further damage from occurring during repeat washing. The burst strength, although improved after subsequent sol-gel treatment, was still poor and would not have met commercial machine wash care standards [24]. This would suggest that too much damage was done to the wool fibre during the enzyme pre-treatment stage. Therefore, the concentration of reducing agent and enzyme in the pre-treatment liquor was lowered to $0.02 \mathrm{M}$ and $50 \mu \mathrm{L} / \mathrm{L}$ respectively, giving a weight loss of $4.96 \%$ (see Table 3 ). Less damage to the fibre was observed and only a further $2.17 \%$ weight loss was incurred during washing, giving a burst strength $275 \mathrm{kPa}$ and the shrink resistance was $8.7 \%$. Subsequent treatment with sol improved the shrink resistance with the $1: 1$ dilution achieving less than $2 \%$ and the $2: 1$ dilution achieving less than $1 \%$, both with an improvement in strength achieved. The SEM images in Figures 4 and 5 confirm less damage to the wool fibre when the concentrations of enzyme and reducing agent in the pretreatment liquor were lowered. These results again show that durability on wool of sol-gel containing MPTMS was better than sol-gel containing GPTMS, with a greater quantity of the MPTMS based sol-gel remaining on the wool fibre surface after washing in comparison to the quantity of GPTMS based sol-gel remaining on the wool fibre surface after washing. The SEM images coupled with EDX elemental analysis for silicon, illustrated in Figures 6 and 7 showed uniformity of elemental silicon on the wool fibre surface suggesting a uniform solgel finish. After washing, the SEM-EDX image in Figure $6 \mathrm{~b}$ for wool treated with a GPTMS based sol-gel showed a reduction in elemental silicon content, while washing did not appear 
to effect the elemental silicon content on the wool treated with a MPTMS based sol-gel as illustrated in the SEM-EDX image in Figure 7b. The individual coating particles from sol-gel finishing deposited on the treated wool fibre can be observed in the SEM images illustrated in Figure 5, especially after treatment with a 2:1 dilution of sol. The particles are of different size due to aggregation and further work is required in developing a deposition of uniformly sized particles.

[Figure 3, Figure 4, Figure 5, Figure 6, Figure 7, Table 3 and Table 4 near here] As observed previously $[4,10]$, an improvement in the CIE Whiteness Index was observed for wool treated with protease (Table 4). The higher the concentration of protease, the higher the whiteness index value. The results in Table 4 show that further improvement in whiteness was achieved if protease treated wool was subsequently treated with sol-gel containing MPTMS. When protease treated wool was subsequently treated with sol-gel containing GPTMS, the level of whiteness was retained. This shows an advantage of treating wool with protease and sol-gel is that a shrink-resist finish can be achieved with no yellowing of the wool fibre. A drawback of conventional chlorine-resin methods of achieving shrinkresistance is significant yellowing of the wool fibre due to the use of chlorine or the disodium salt of dichloroisocyanuric acid (DCCA) [28, 29]. Studies using alternative methods to achieve shrink-resistant wool such as siloxanes [26] or polyurethane modified with 3aminopropyltriethoxysilane [19] have also resulted in the yellowing of the wool fibre.

An improvement in hydrophobicity was observed (Table 4) after treatment of wool with the sol-gel finishes, as represented by the increase in water rating number. This would be expected due to the presence of long chain hydrocarbons present in the octyl triethoxysilane (OTES) and dimethyloctadecyl [3-(trimethoxysilyl)propyl] ammonium chloride (QUAT) used in the sol-gel formulation. Previous studies have also demonstrated that the alkyl chain 
length in the sol-gel influences the surface hydrophobicity of treated [30-31]. Washing of the sol-gel treated wool samples showed some loss in hydrophobicity. As well as contributing to an increase in hydrophobicity, the presence of QUAT in the sol-gel may impart an antimicrobial effect on the treated wool, as observed on cotton treated with the presence of QUAT in the sol-gel formulation [20].

When added to the hybrid sol, MPTMS showed better performance when treated on wool than when GPTMS was added to the hybrid sol. The thiol group on wool is more active to work with the mercapto group on MPTMS than the epoxy group on GPTMS leading to more effective cross-linking with fibre. The mercapto groups are more effective at cross-linking with themselves therefore leading to a more uniform coating leading to better shrink resistance. Unlike epoxy groups, mercapto groups have a reducing effect which may degrade the cuticle scale on wool therefore contributing to an improvement in shrink-resistant properties.

\section{Conclusions}

The combination of enzyme treatment and sol-gel polymer coating has the potential to produce lighter and softer knitted wool fabrics with durable shrink-resistance and improved whiteness. Due to the use of an immersion treatment for sol-gel application on fabric rather the conventional pad only method, a soft handle can be achieved by the deposition of the solgel polymer on the individual wool fibre rather than adhering together adjacent fibres within a knitted wool structure. The pre-treatment of wool with sodium sulphite can break down disulphide bonds in the cystine linkages on wool to form thiol groups, resulting in the promotion of reaction bonding between the thiol groups in MPTMS and those on the wool. The cross-linking within the wool fibre can be re-established with the hybrid sol-gel network. 
The addition of MPTMS as a coupling group within the hybrid sol-gel gave better performance than using GPTMS in terms of polymer uptake, fabric shrink resistance, whiteness and durability to washing.

\section{References}

1. J. Shen in "Advances in Textile Biotechnology", (V. A. Nierstrasz, and A. CavacoPaulo Eds.), pp.171-192, Woodhead Publishing, Cambridge, 2010.

2. H. Nolte, D. P. Bishop, and H. Höcker, J. Text. I., 87, 212 (1996).

3. J. Shen, D. Bishop, E. Heine, and B. Hollfelder, J. Text. I., 90, 404 (1999).

4. E. Smith and J. Shen, J. Biotechnol., 156, 134 (2011).

5. E. Smith and J. Shen, Biocatal. Biotransfor., 30, 38 (2012).

6. S. Vílchez, P. Jovancic, A. M. Manich, M. R. Julià, and P. Erra, J. Appl. Polym. Sci., 98, 1938 (2005).

7. S. Vílchez, A. M. Manich, P. Jovancic, and P. Erra, Carbohyd. Polym., 71, 515 (2008).

8. C. J. S. M. Silva, Q. Zhang, J. Shen, and A. Cavaco-Paulo, Enzyme Microb. Tech., 39, 634 (2006).

9. E. Smith, Q. Zhang, J. Shen, M. Schroeder, and C. Silva, Biocatal. Biotransfor., 26, 391 (2008).

10. E. Smith, M. Schroeder, G. Guebitz, and J. Shen, Enzyme Microb. Tech., 47, 105 (2010).

11. R. Araújo, C. Silva, R. Machado, M. Casal, A. M. Cunha, J. C. Rodriguez-Cabello and A. Cavaco-Paulo, Biomacromolecules, 10, 1655 (2009). 
12. B. Simončič, B. Tomšič, B. Orel, and I. Jerman in "Surface Modification Systems for Creating Stimuli Responsiveness of Textiles”, (D. Jocic Ed.), pp. 17-34, University of Twente, Enschede, 2010.

13. B. Mahltig, H. Haufe, and H. Böttcher, J. Mater. Chem., 15, 4385 (2005).

14. B. Mahltig and H. Böttcher, J. Sol-Gel Sci. Techn., 27, 43 (2003).

15. W. A. Daoud, J. H. Xin, and X. Tao, J. Am. Ceram. Soc., 87, 1782 (2004).

16. H. Wang, J. Ding, Y. Xue, X. Wang, and T. Lin, J. Mater. Res., 25, 1336 (2010).

17. T. Textor, T. Bahners, and E. Schollmeyer, in "Proceedings of the $10^{\text {th }}$ International Wool Research Conference”, Fl-12, pp.1-5, Aachen, 26 ${ }^{\text {th }}$ November $-1^{\text {st }}$ December 2000.

18. K. Yan, H. Jiang, and C. Ding, in "Proceedings of the $11^{\text {th }}$ International Wool Research Conference”, 12KN, pp.1-10, Leeds, $4^{\text {th }}-9^{\text {th }}$ September 2005.

19. H. Yi and K. Yan, J. Appl. Polym. Sci., 109, 2169 (2008).

20. M. M. Chizyuka, Ph. D. Thesis, De Montfort University, Leicester, 2016.

21. S.J. McNeil and O. C. Standard, Text. Res. J.,87, 607 (2017).

22. T. Bahners, J. Adhes. Sci. Technol., 25, 2005 (2011).

23. B. Mahltig in "Functional Finishes for Textiles Improving Comfort Performance and Protection” (R. Paul Ed.), pp. 387-423, Woodhead Publishing, Cambridge, 2015.

24. R. S. Carran, A. Ghosh, and J. M. Dyer, Appl. Surf. Sci., 287, 467 (2013).

25. Woolmark Company “Woolmark Specification, Knitted Fabric, Specification SF-1”, The Woolmark Company, Australia, 2016.

26. F. Nickel, G. Koerner, G. Schmidt, and H. Rott, U. S. Patent 4405328 (1983).

27. R. W. Moncrieff, "Wool Shrinkage and its Prevention" The National Trade Press, London, 1953. 
28. D. M. Lewis in “Wool Dyeing” (D. M. Lewis Ed.), pp. 111-136, Society of Dyers and Colourists, Bradford, 1992.

29. K. R. Millington in "Advances in Wool Technology” (N. A. G. Johnson, \& I. M. Russell Eds.), pp.217-247, Woodhead Publishing, Cambridge, 2009.

30. S. J. McNeil, O. C. Standard and M. T. Pailthorpe, in "Proceedings of the $11^{\text {th }}$ International Wool Research Conference”, $47 \mathrm{CCF}$, pp.1-9, Leeds, $4^{\text {th }}-9^{\text {th }}$ September 2005.

31. H. Wang, J Ding, T. Lin and X. Wang, Res. J. Text. Apparel, 14 (2), 30 (2010). 
Table 1. Test liquids used for the Water Rating Number (WRN) wettability test.

\begin{tabular}{cc}
\hline $\begin{array}{c}\text { Water Rating Number } \\
\text { Concentration of iso-propanol } \\
(\%)\end{array}$ \\
\hline 0 & 0 \\
\hline 1 & 2 \\
\hline 2 & 5 \\
\hline 3 & 10 \\
\hline 3.5 & 15 \\
\hline 4 & 20 \\
\hline 4.5 & 25 \\
\hline 5 & 30 \\
\hline
\end{tabular}


Table 2. Effect of pre-treatment and subsequent sol-gel treatments on weight loss (gain), felting shrinkage and burst strength of wool fabrics.

\begin{tabular}{|c|c|c|c|c|c|c|c|c|}
\hline \multirow{2}{*}{ Pre-treatment } & \multirow{2}{*}{$\begin{array}{l}\text { Average } \\
\text { weight loss } \\
\text { due to pre- } \\
\text { treatment } \\
(\%)\end{array}$} & \multirow{2}{*}{$\begin{array}{l}\text { Sol-gel } \\
\text { treatment } \\
\text { ( } 2: 1 \text { dilution } \\
\text { sol to water) }\end{array}$} & \multirow{2}{*}{$\begin{array}{l}\text { Weight } \\
\text { gain due to } \\
\text { sol-gel } \\
\text { treatment } \\
(\%)\end{array}$} & \multirow{2}{*}{$\begin{array}{c}\text { CIE } \\
\text { Whiteness } \\
\text { Index }\end{array}$} & \multicolumn{2}{|c|}{$\begin{array}{c}\text { Area shrinkage } \\
(\%)\end{array}$} & \multirow{2}{*}{$\begin{array}{l}\text { Weight } \\
\text { loss due to } \\
\text { washes } \\
(\%)\end{array}$} & \multirow{2}{*}{$\begin{array}{c}\text { Burst } \\
\text { strength } \\
\text { after } \\
\text { washes } \\
(\mathrm{kPa})\end{array}$} \\
\hline & & & & & $7 \mathrm{~A}$ & $3 \times 5 \mathrm{~A}$ & & \\
\hline \multirow{3}{*}{$\begin{array}{l}\text { Scouring } \\
\text { with } 2 \mathrm{~g} / \mathrm{L} \\
\text { UPL }\end{array}$} & \multirow{3}{*}{$\begin{array}{c}0.51 \\
( \pm 0.09)\end{array}$} & None & 0 & -2.00 & -0.24 & 16.61 & 1.44 & 431 \\
\hline & & $\begin{array}{l}\text { Sol with } \\
\text { GPTMS }\end{array}$ & 1.79 & 8.89 & 0 & 7.35 & 3.39 & 447 \\
\hline & & $\begin{array}{l}\text { Sol with } \\
\text { MPTMS }\end{array}$ & 6.95 & 21.53 & 0.23 & 1.31 & 3.61 & 394 \\
\hline \multirow{3}{*}{$\begin{array}{l}\text { Scouring } \\
\text { with } 2 \mathrm{~g} / \mathrm{L} \\
\text { UPL and } \\
0.05 \mathrm{M} \\
\text { sulphite }\end{array}$} & \multirow{3}{*}{$\begin{array}{c}0.69 \\
( \pm 0.16)\end{array}$} & None & 0 & 6.56 & 5.35 & 14.76 & 1.43 & 337 \\
\hline & & $\begin{array}{l}\text { Sol with } \\
\text { GPTMS }\end{array}$ & 6.23 & 6.50 & 1.51 & 3.66 & 3.41 & 406 \\
\hline & & $\begin{array}{l}\text { Sol with } \\
\text { MPTMS }\end{array}$ & 12.27 & 24.11 & -0.70 & 2.63 & 3.71 & 382 \\
\hline \multirow{3}{*}{$\begin{array}{l}\text { Scouring } \\
\text { with } 2 \mathrm{~g} / \mathrm{L} \\
\text { UPL, } 0.05 \mathrm{M} \\
\text { sulphite and } \\
100 \mu \mathrm{L} / \mathrm{L} \\
\text { protease }\end{array}$} & \multirow{3}{*}{$\begin{array}{c}17.98 \\
( \pm 3.47)\end{array}$} & None & 0 & 29.25 & -3.33 & 4.45 & 21.78 & 133 \\
\hline & & $\begin{array}{l}\text { Sol with } \\
\text { GPTMS }\end{array}$ & 4.50 & 28.50 & 1.91 & 0.95 & 3.23 & 186 \\
\hline & & $\begin{array}{l}\text { Sol with } \\
\text { MPTMS }\end{array}$ & 8.41 & 34.71 & -0.20 & 0.03 & 4.48 & 170 \\
\hline
\end{tabular}


Table 3. Effect of pre-treatment with a lowered amount of enzyme and reducing agent and the subsequent sol-gel treatments on weight loss (gain), felting shrinkage and burst strength of wool fabrics.

\begin{tabular}{|c|c|c|c|c|c|c|c|}
\hline \multirow{2}{*}{$\begin{array}{l}\text { Pre- } \\
\text { treatment }\end{array}$} & \multirow{2}{*}{$\begin{array}{c}\text { Average } \\
\text { weight } \\
\text { loss due to } \\
\text { pre- } \\
\text { treatment } \\
(\%) \\
\end{array}$} & \multirow{2}{*}{$\begin{array}{l}\text { sol-gel } \\
\text { treatment }\end{array}$} & \multirow{2}{*}{$\begin{array}{l}\text { Weight } \\
\text { gain }(\%) \\
\text { due to } \\
\text { sol-gel } \\
\text { treatment }\end{array}$} & \multicolumn{2}{|c|}{$\begin{array}{c}\text { Area } \\
\text { shrinkage } \\
(\%) \\
\end{array}$} & \multirow{2}{*}{$\begin{array}{l}\text { Weight } \\
\text { loss due to } \\
\text { washes } \\
(\%)\end{array}$} & \multirow{2}{*}{$\begin{array}{c}\text { Burst } \\
\text { strength } \\
\text { after } \\
\text { washes } \\
(\mathrm{kPa})\end{array}$} \\
\hline & & & & $7 \mathrm{~A}$ & $3 \times 5 A$ & & \\
\hline \multirow{5}{*}{$\begin{array}{l}\text { Scouring } \\
\text { with } 2 \mathrm{~g} / \mathrm{L} \\
\mathrm{UPL}, \\
0.02 \mathrm{M} \\
\text { sulphite } \\
\text { and } \\
50 \mu \mathrm{L} / \mathrm{L} \\
\text { protease }\end{array}$} & \multirow{5}{*}{$\begin{array}{c}4.96 \\
( \pm 0.40)\end{array}$} & none & 0 & 0.64 & 8.73 & 2.17 & 275 \\
\hline & & $\begin{array}{l}\text { 1:1 dilution } \\
\text { sol with } \\
\text { GPTMS to } \\
\text { water }\end{array}$ & 0.94 & 1.80 & 1.89 & 1.47 & 292 \\
\hline & & $\begin{array}{l}2: 1 \text { dilution } \\
\text { sol with } \\
\text { GPTMS to } \\
\text { water }\end{array}$ & 10.13 & 0.87 & 0.69 & 3.87 & 309 \\
\hline & & $\begin{array}{l}1: 1 \text { dilution } \\
\text { sol with } \\
\text { MPTMS to } \\
\text { water }\end{array}$ & 3.91 & 1.10 & 1.13 & 0.81 & 316 \\
\hline & & $\begin{array}{l}2: 1 \text { dilution } \\
\text { sol with } \\
\text { MPTMS to } \\
\text { water }\end{array}$ & 15.47 & 0.58 & -0.73 & 1.95 & 305 \\
\hline
\end{tabular}


Table 4. CIE Whiteness Index and water rating index values of wool fibre before and after treatment with sol-gel finish.

\begin{tabular}{|c|c|c|c|c|}
\hline \multirow{2}{*}{ Pre-treatment } & \multirow{2}{*}{$\begin{array}{l}\text { Subsequent sol-gel } \\
\text { treatment }\end{array}$} & \multirow{2}{*}{$\begin{array}{l}\text { CIE Whiteness } \\
\text { Index }\end{array}$} & \multicolumn{2}{|c|}{ Water rating number (WRN) } \\
\hline & & & $\begin{array}{c}\text { After sol-gel } \\
\text { treatment }\end{array}$ & $\begin{array}{c}\text { After } 7 \text { A \& } \\
3 \times 5 \text { A washes }\end{array}$ \\
\hline \multirow{3}{*}{$\begin{array}{l}\text { Scouring with } \\
2 \mathrm{~g} / \mathrm{L} \text { UPL }\end{array}$} & none & $-2.00( \pm 0.45)$ & 3 & 3 \\
\hline & $\begin{array}{l}\text { 1:1 dilution sol } \\
\text { with MPTMS to } \\
\text { water }\end{array}$ & $2.92( \pm 0.62)$ & 4 & 3 \\
\hline & $\begin{array}{l}2: 1 \text { dilution sol } \\
\text { with MPTMS to } \\
\text { water }\end{array}$ & $21.53( \pm 0.80)$ & 4 & 3 \\
\hline \multirow{3}{*}{$\begin{array}{l}\text { Scouring with } \\
2 \mathrm{~g} / \mathrm{L} \text { UPL, } \\
0.02 \mathrm{M} \text { sulphite } \\
\text { and } 50 \mu \mathrm{L} / \mathrm{L} \\
\text { protease }\end{array}$} & none & $14.74( \pm 1.20)$ & 3.5 & 3.5 \\
\hline & $\begin{array}{l}\text { 1:1 dilution sol } \\
\text { with MPTMS to } \\
\text { water }\end{array}$ & $18.20( \pm 0.21)$ & 3.5 & 3.5 \\
\hline & $\begin{array}{l}2: 1 \text { dilution sol } \\
\text { with MPTMS to } \\
\text { water }\end{array}$ & $34.07( \pm 0.15)$ & 4 & 3.5 \\
\hline \multirow{3}{*}{$\begin{array}{l}\text { Scouring with } \\
2 \mathrm{~g} / \mathrm{L} \text { UPL }\end{array}$} & none & $-2.00( \pm 0.45)$ & 3 & 3 \\
\hline & $\begin{array}{l}\text { 1:1 dilution sol } \\
\text { with GPTMS to } \\
\text { water }\end{array}$ & $-0.58( \pm 0.52)$ & 4 & 3.5 \\
\hline & $\begin{array}{l}2: 1 \text { dilution sol } \\
\text { with GPTMS to } \\
\text { water }\end{array}$ & $8.89( \pm 0.56)$ & 4 & 3.5 \\
\hline \multirow{3}{*}{$\begin{array}{l}\text { Scouring with } \\
2 \mathrm{~g} / \mathrm{L} \text { UPL, } \\
0.02 \mathrm{M} \text { sulphite } \\
\text { and } 50 \mu \mathrm{L} / \mathrm{L} \\
\text { protease }\end{array}$} & none & $14.74( \pm 1.20))$ & 3.5 & 3.5 \\
\hline & $\begin{array}{l}\text { 1:1 dilution sol } \\
\text { with GPTMS to } \\
\text { water }\end{array}$ & $12.19( \pm 1.01)$ & 3.5 & 3.5 \\
\hline & $\begin{array}{l}2: 1 \text { dilution sol } \\
\text { with GPTMS to } \\
\text { water }\end{array}$ & $28.32( \pm 0.57$ & 4 & 3.5 \\
\hline
\end{tabular}




\section{Figure Captions}

Figure 1. SEM images of wool scoured with $2 \mathrm{~g} / \mathrm{L}$ UPL then followed by treatment with a $2: 1$ dilution of sol-gel containing either GPTMS or MPTMS: before washing and after 7A and $3 \times 5 \mathrm{~A}$ washes.

Figure 2. SEM images of wool scoured with $2 \mathrm{~g} / \mathrm{L}$ UPL in the presence of $0.05 \mathrm{M}$ sodium sulphite (a) and followed by treatment with a 2:1 dilution of sol containing MPTMS before washing (b and c) and after 7A \& 3x5A washes (d).

Figure 3. SEM images of wool scoured with $2 \mathrm{~g} / \mathrm{L}$ UPL in the presence of $0.05 \mathrm{M}$ sodium sulphite and $100 \mu \mathrm{L} / \mathrm{L}$ protease then followed by treatment with a $2: 1$ dilution of sol containing MPTMS: before washing and after 7A \& 3x5A washes.

Figure 4. SEM images of wool scoured with $2 \mathrm{~g} / \mathrm{L}$ UPL in the presence of $0.02 \mathrm{M}$ sodium sulphite and $50 \mu \mathrm{L} / \mathrm{L}$ protease then followed by treatment with either a $1: 1$ or a $2: 1$ dilution of sol containing GPTMS: before washing and after 7A \& 3x5A washes .

Figure 5. SEM images of wool scoured with $2 \mathrm{~g} / \mathrm{L}$ UPL in the presence of $0.02 \mathrm{M}$ sodium sulphite and $50 \mu \mathrm{L} / \mathrm{L}$ protease then followed by treatment with either a 1:1 or a $2: 1$ dilution of sol containing MPTMS: before washing and after 7A \& 3x5A washes.

Figure 6. SEM-EDX detected elements of $\mathrm{Si}$ on the surface of wool fabrics scoured with 2 $\mathrm{g} / \mathrm{L}$ in the presence of $0.02 \mathrm{M}$ sodium sulphite and $50 \mu \mathrm{L} / \mathrm{L}$ protease then followed by treatment with 2:1 dilution of sol containing GPTMS before washing (a) and after 7A \& $3 \times 5 A$ washes (b).

Figure 7. SEM-EDX detected elements of $\mathrm{Si}$ on the surface of wool fabrics scoured with 2 $\mathrm{g} / \mathrm{L}$ in the presence of $0.02 \mathrm{M}$ sodium sulphite and $50 \mu \mathrm{L} / \mathrm{L}$ protease then followed by treatment with 2:1 dilution of sol containing MPTMS before washing (a) and after 7A \& $3 \times 5 A$ washes (b). 
<smiles>O=C(O)ONCO</smiles><smiles></smiles>
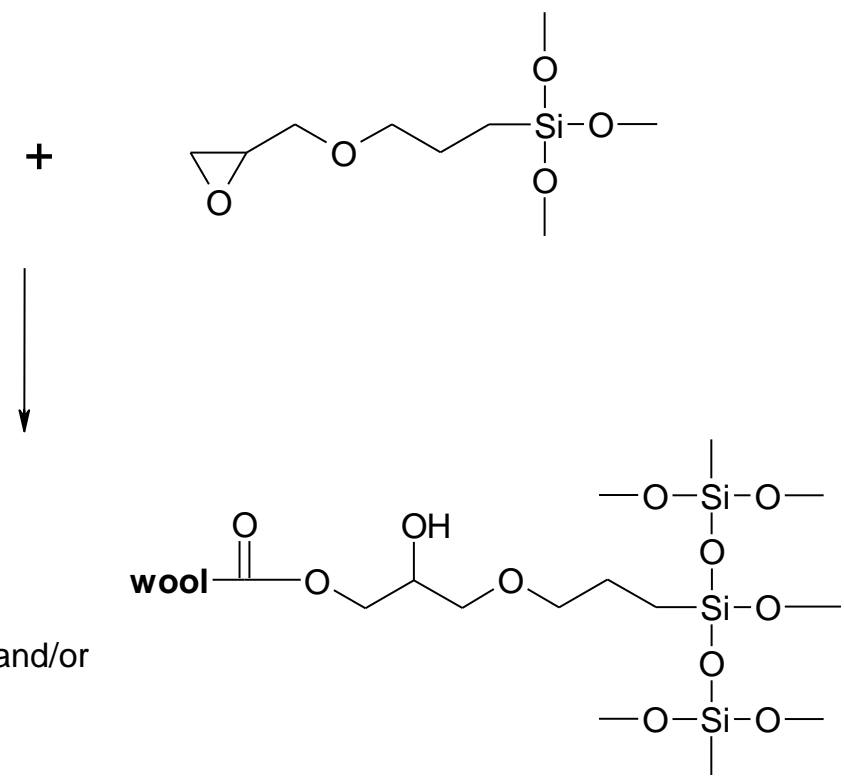

Scheme 1. Possible reaction of 3-glycidyloxypropyl trimethoxysilane (GPTMS) with wool. 


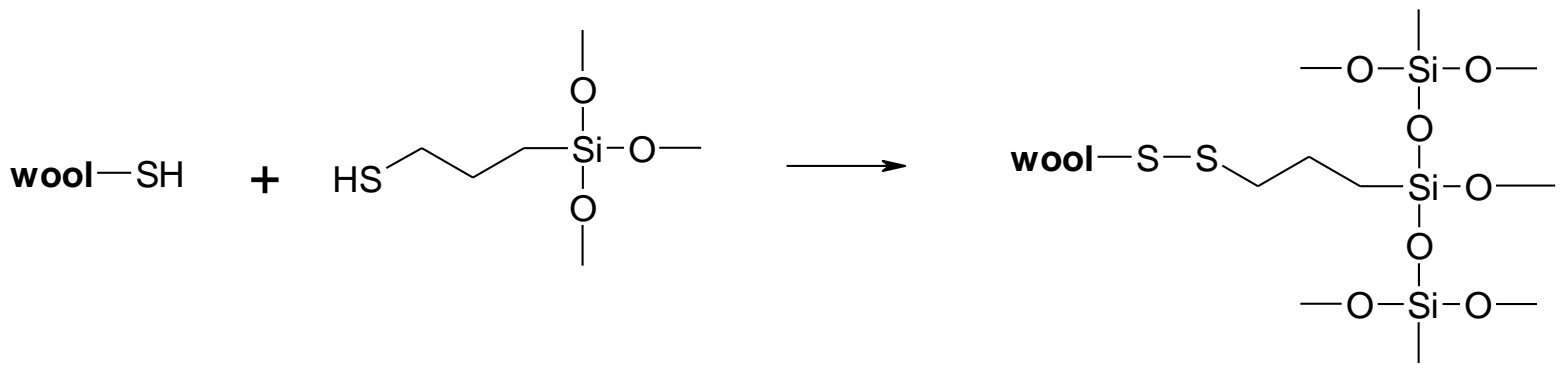

Scheme 2. Possible reaction of 3-mercaptopropyl trimethoxysilane (MPTMS) with wool. 


Treatment
wool scoured
with 2g/L UPL
wool scoured
with 2g/L UPL
and subsequently
treated with a $2: 1$
dilution of sol
with GPTMS to
water
wool scoured
with 2g/L UPL
and subsequently
treated with a 2:1
dilution of sol
with MPTMS to
water

Figure 1. 


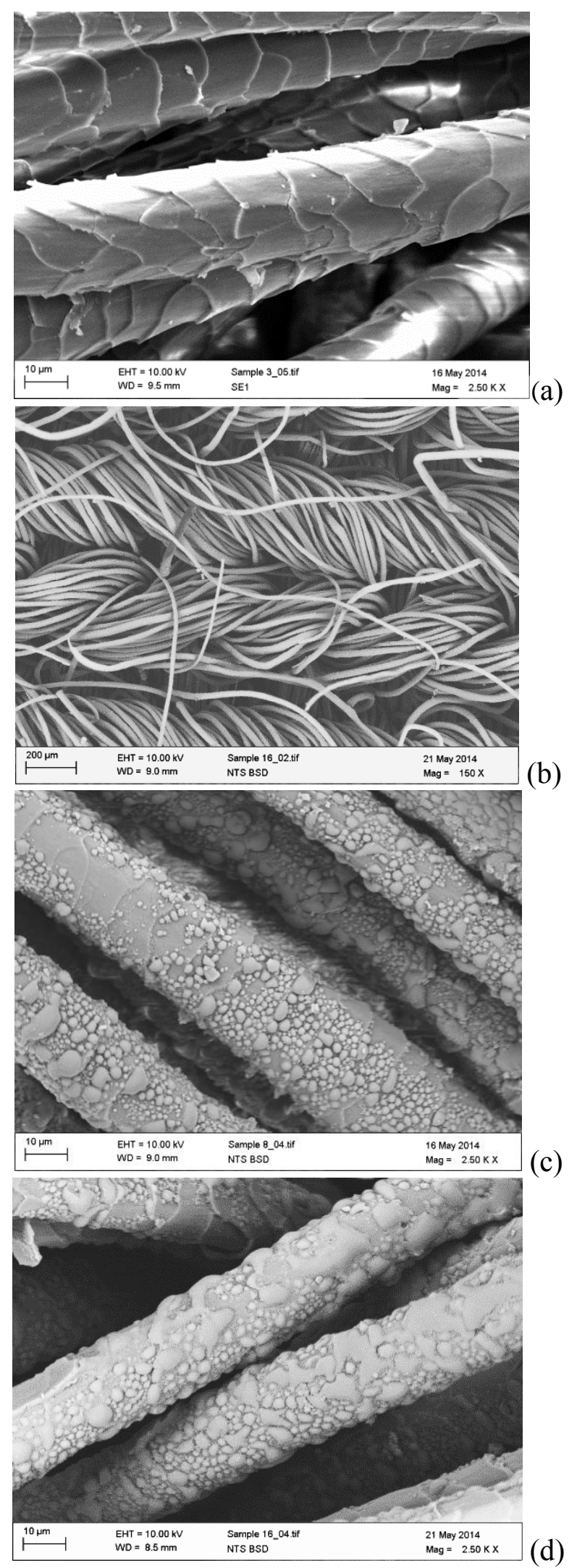

Figure 2. 


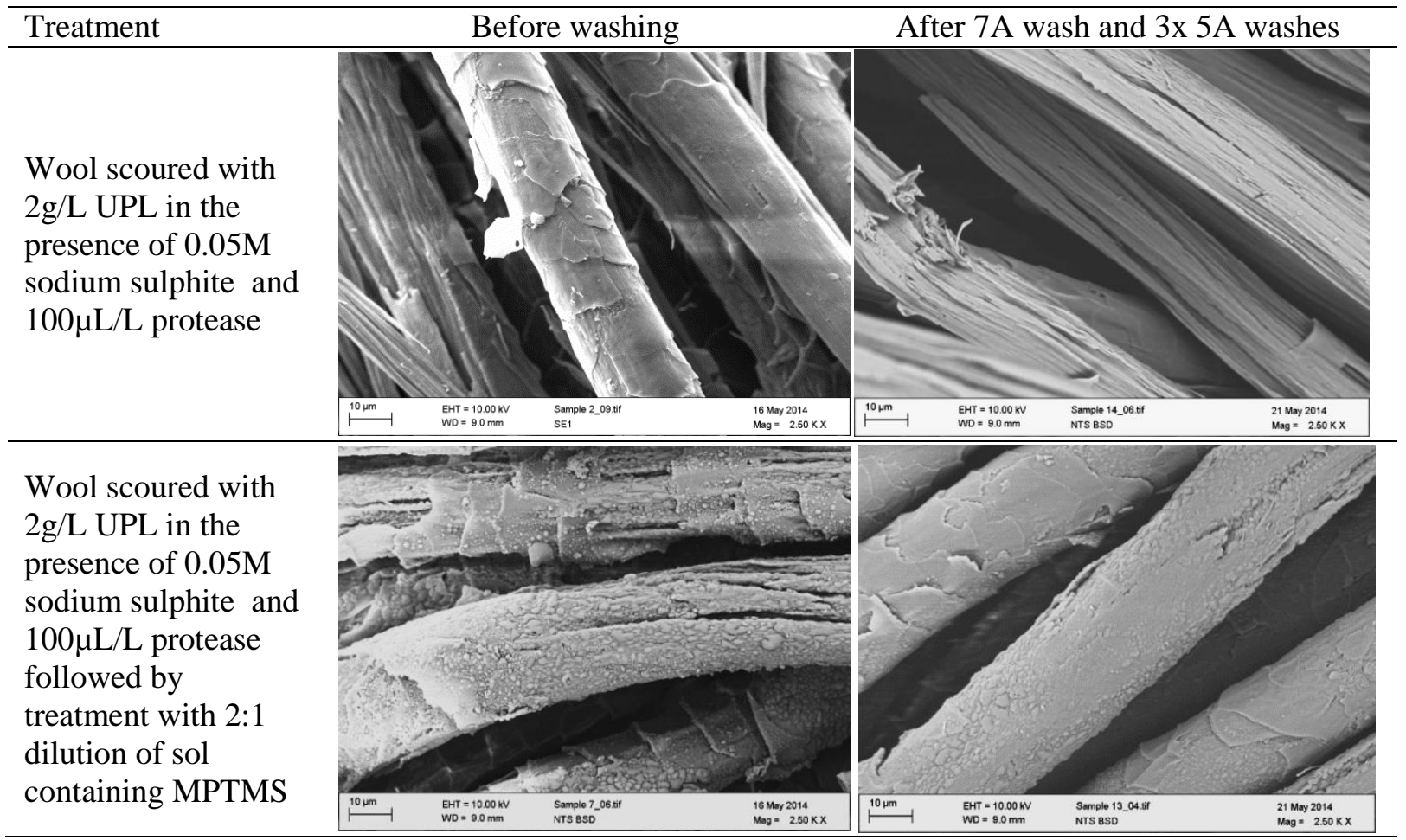

Figure 3. 


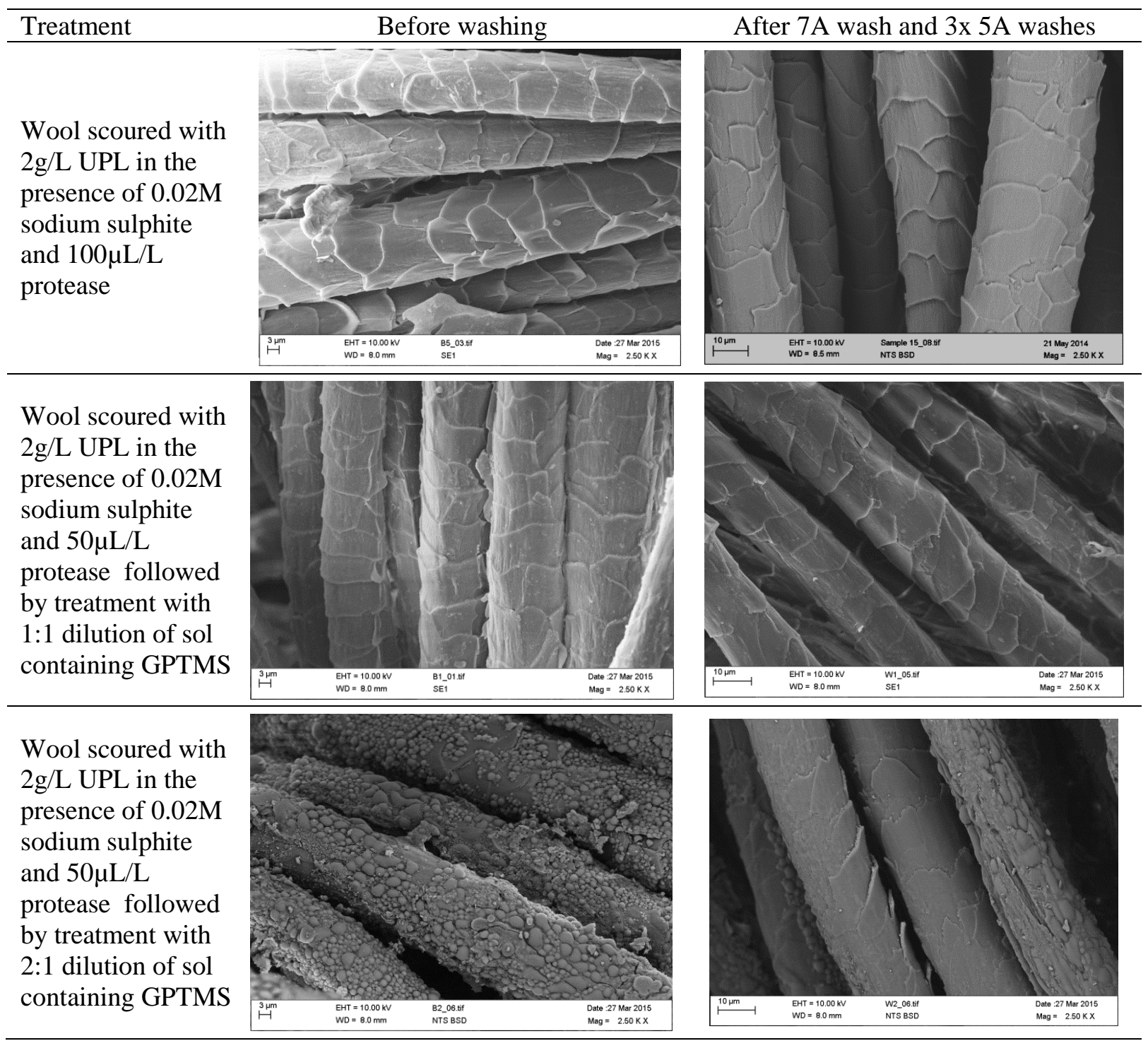

Figure 4. 


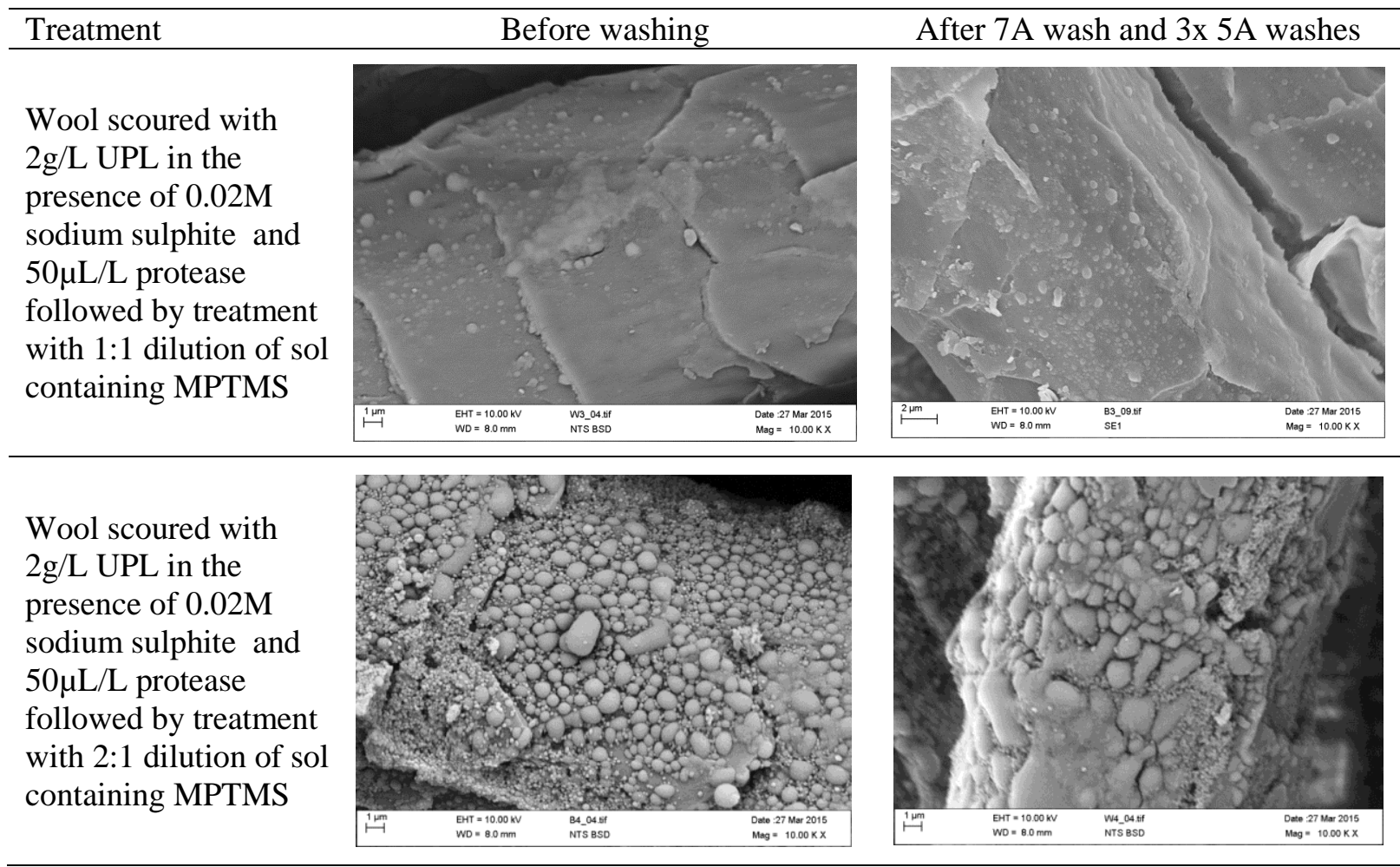

Figure 5. 


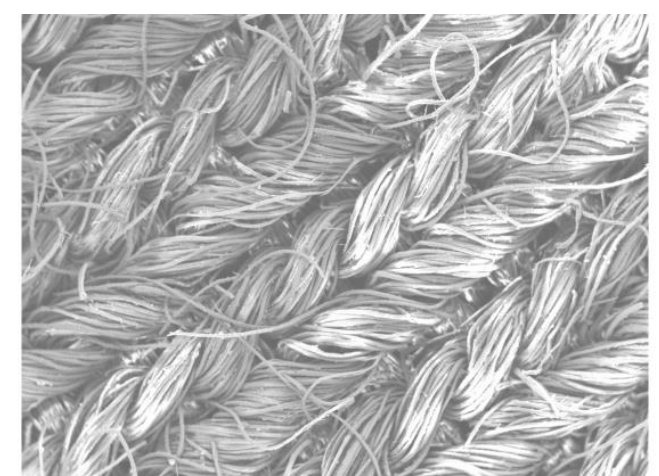

Electron Image 1

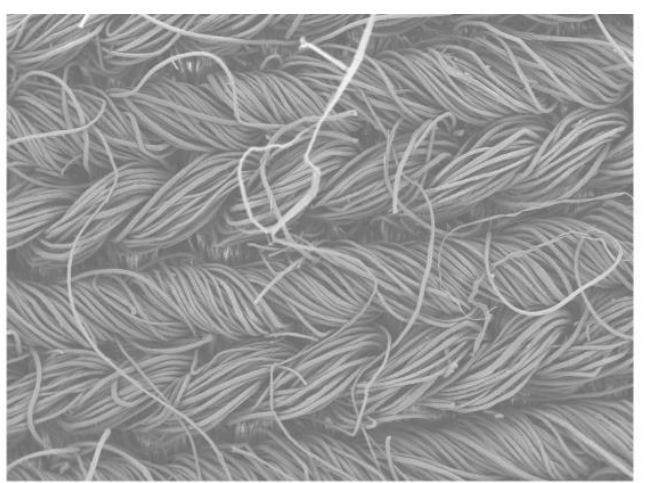

Electron Image 1

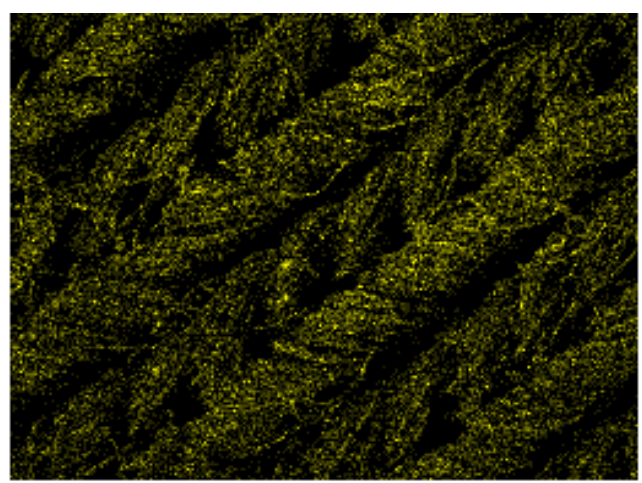

(a)

Si Ka1

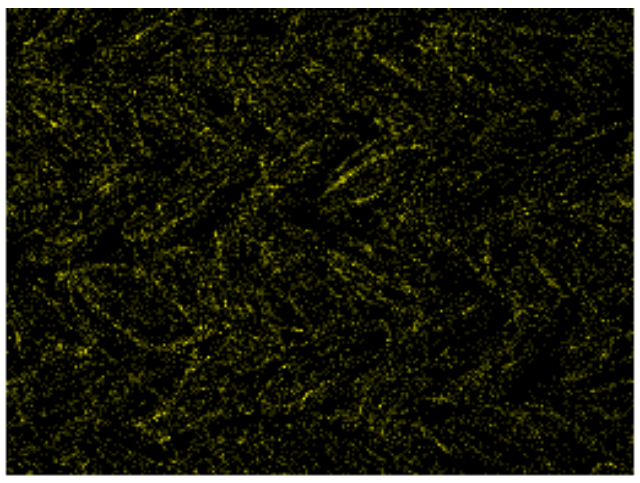

(b)

Si Ka1

\section{Figure 6.}




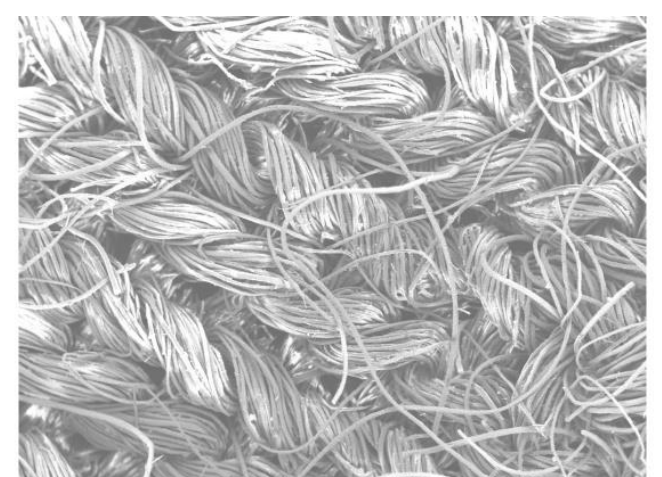

Electron Image 1

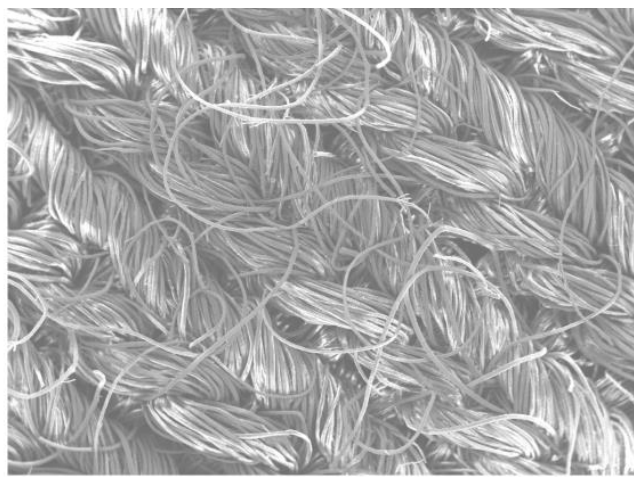

Electron Image 1

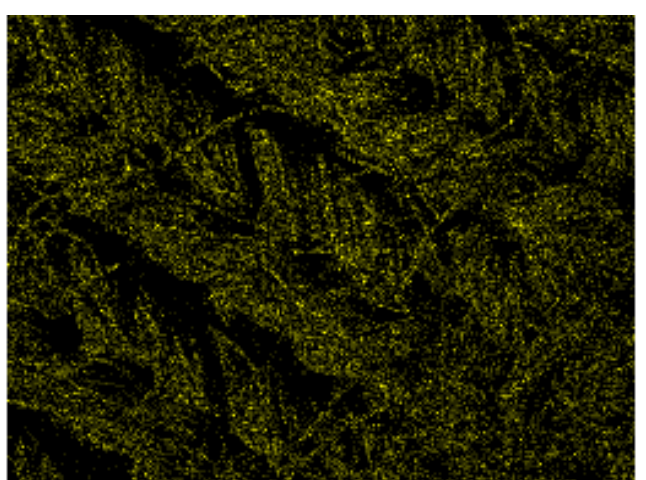

Si Ka1

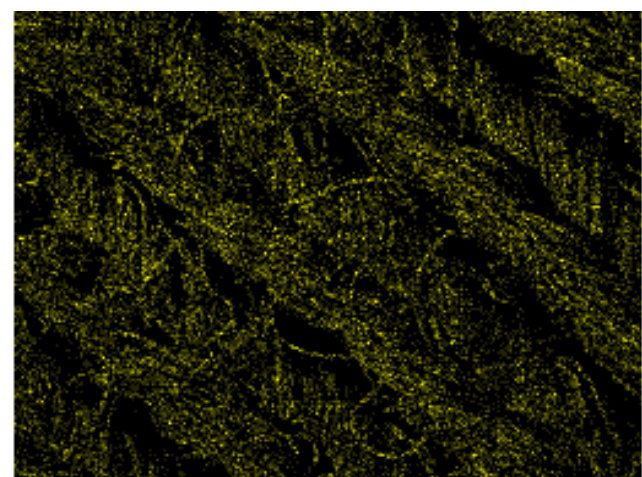

Si Ka1

(a)

Figure 7. 